\title{
Attending of AJA University of Medical Sciences Researchers to the 42nd World Congress of the International Committee of Military Medicine
}

\author{
Zahra Farsi ${ }^{1,}$ \\ ${ }^{1}$ Ph.D., Associate Professor, Faculty of Nursing, AJA University of Medical Sciences, Tehran, IR Iran \\ "Corresponding author: Zahra Farsi, BScN, MScN, Ph.D., Associate Professor, Faculty of Nursing, AJA University of Medical Sciences, Kaj St., Shariati St, Tehran, IR Iran. Tel: \\ +98-2177500404;+98-2177500929, E-mail: zahrafarsi@gmail.com
}

Received 2017 December 15; Accepted 2017 December 17.

The first international congress of military medicine and pharmacy was held in July 1921, in Brussels, Belgium. The international committee on military medicine (ICMM) is an international and intergovernmental organization constituted by more than 100 States including I. R. Iran (1). The 42nd world congress of the ICMM was held at Vigyan Bhawan, New Delhi, India, from 19th to 24th November 2017 and delegates from all over the world met in India. The congress was hosted by the armed forces medical services, ministry of defence, India. The congress had simultaneous scientific sessions, poster presentations, roundtables, panel discussions, and workshops encompassing the broad themes (2). Iranian researchers of AJA University of Medical Sciences attended to the 42nd World Congress of ICMM and presented their scientific papers in the field of military medicine in the scientific sessions, poster presentations, roundtables, and panel discussions (Figure 1).

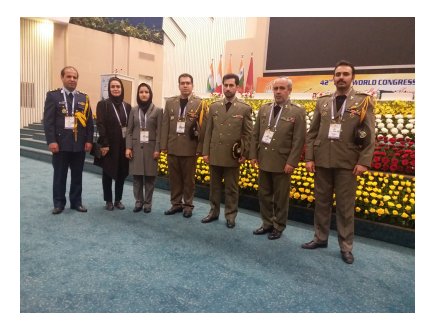

Figure 1. Researchers of AJA University of Medical Sciences in the 42nd World Congress of ICMM

The contribution of Iranian researchers of AJA University of Medical Sciences in the congress was as follows:

A lecture was presented by Dr. Zahra Farsi (Figure 2) on 21st Nov 2017 titled "Experiences of health care providers in the Iran-Iraq war: a content analysis study".

A lecture was presented by Dr. Bita Rohani (Figure 3) on 21st Nov 2017 titled "Oral and maxillofacial diseases preva-

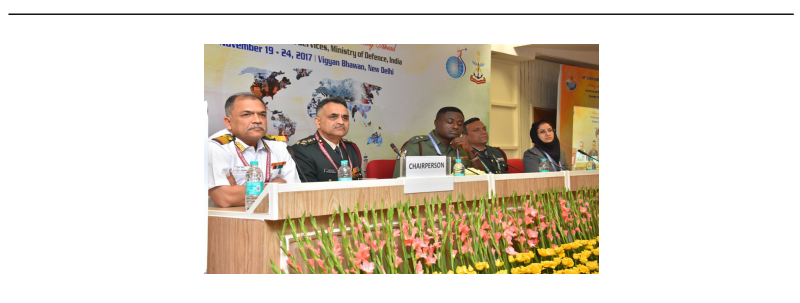

$\overline{\text { Figure 2. Oral presentation by Dr. Zahra Farsi in the 42nd World Congress of ICMM }}$

lence in Iranian Navy Drivers."

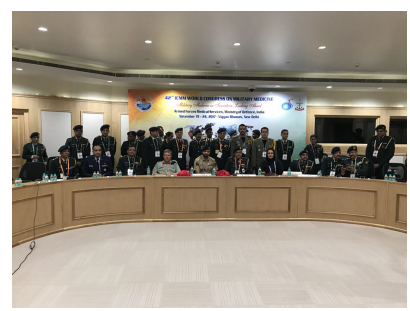

Figure 3. Oral presentation by Dr. Bita Rohani in the 42nd World Congress of ICMM

A poster was presented by Dr. Masoud Jabari and Dr. Zahra Farsi (Figure 4) on 21st Nov 2017 titled "Exploring coping strategies of health care providers with tension sources in Iran-Iraq war: a qualitative study."

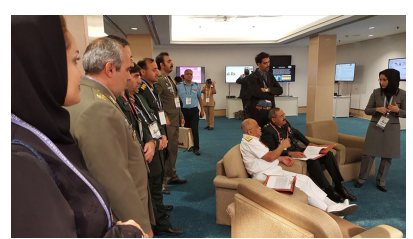

Figure 4. Poster Presentation by Dr. Zahra Farsi and Dr. Masoud Jabari in the 42nd World Congress of ICMM 
A poster was presented by Dr. Amir Khoshvaghti (Figure 5) on 21st Nov 2017 titled "Skin wound healing and oxygen (hyperbaric or topical)”.

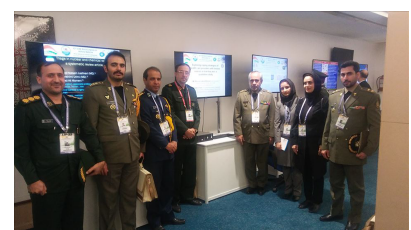

Figure 5. Poster presentation by Dr. Amir Khoshvaghti in the 42nd World Congress of ICMM

A poster was presented by Dr. Sepehr Ebrahimi and Mohammad Ali Momeni (Figure 6) on 21st Nov 2017 titled "Triage in nuclear and chemical wars: A systematic review".

The closing ceremony of ICMM 2017 was held on Nov 24th, 2017 (Figure 6).

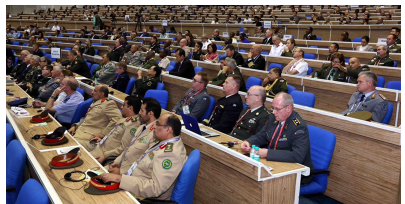

Figure 6. The closing Ceremony of the 42nd World Congress of ICMM

It should be noted that the 43rd world congress on military medicine will be held in Basel, Switzerland, from 19th to 24th May 2019 (2) and the 4th ICMM Pan-Asia Pacific congress on military medicine will be held in Iran (27-31th October 2018) (3, 4).

\section{Acknowledgments}

The author would like to thank all of the participants in this study.

\section{Footnotes}

Authors' Contribution: Zahra Farsi involved in the planning, data collection, data analysis, and writing the paper. Financial Disclosure: The author declares that she has no competing interests.

\section{References}

1. International Committee of Military Medicine . International committee of military medicine, historic. Switzerland: ICMM; 2017. Available from: http://www.cimm-icmm.org/page/anglais/historicTxte.php.

2. ICMM . International committee of military medicine, report of the 42nd ICMM world congress on military medicine. Switzerland: ICMM; 2017. Available from: http://www.cimm-icmm.org/page/anglais/ Rapport42emeCongresMondialInde2017ANG.php.

3. Pan Asia Pacific Regional Working Group . International committee of military medicine, international congress on military medicine of the pan Asia Pacific regional working group. Switzerland: ICMM; 2017. Available from: http://www.cimm-icmm.org/page/anglais/ RegionalCongressesANG/panasia.php.

4. Najafipour F. Invitation to the 4th Asia Pacific congress of the Asia Pacific military medicine, (PAPCMM).J Arch Mil Med. 2017;5(3):14471. doi: 10.5812/jamm.14471. 